\title{
التعريب وأثره في تعليم اللغة العربية لغير الناطقين بها
}

\author{
مُحمَّمَ زينوري \\ قسم تدريس اللغة العربية جامعة سوراكرزا الإسلامية الحكومية
}

zaenuri_eljawiy@yahoo.com

\begin{abstract}
This paper aims to explain ta'rib which is a term from Arabic linguistics. In addition, this paper will also explain how the implications of learning about learning Arabic for non-Arabic learners. Ta'rib is the absorption of new words and terms from non-Arabic languages to Arabic by changing their pronunciation to follow patterns and rules in Arabic. Ta'rib can be done in two ways, first forming a new term to replace foreign terms, the two using foreign languages with Arabic patterns that are in accordance with the stipulated conditions. The implication ta'rib of learning Arabic for learners from outside the Arab world includes 1) giving mufradatfusha before the mufradat 'amiyyah;2) emphasize students to use Arabic fusha; 3) emphasize students to look for a translation in the dictionary before absorbing it directly; 4) introducing examples of foreign vocabulary that do not have equivalents in Arabic; 5) explain the provisions that apply to the owner ta'rib before Arabic language learning takes place; 6) emphasizes on students to pay attention to the rules of writing Latin letters that do not have equivalents in Arabic.
\end{abstract}

Keywords: Ta'rib, Effect, Learning Arabic

العـالم في أنشــطة عالميـة مثـل التجاريــة

المقدمة

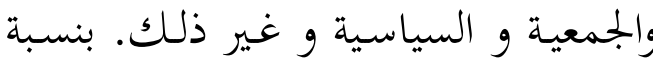

اللغة العربية هي لغة عالمية التي قد

لنشـــــالعربيـة إلى خــارج العـرب وكثــرة

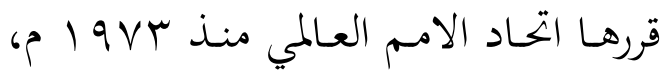

ناطقين بغير العربية يتحدثون بها فظهرت

حسى صـارت أغـراض تعلـيم اللغـة العربيـة

المشـكلات في اسـتعمالها خاصـة حسول

لغـير النـاطقين بهــا ليســت كلغـة الــدين

ناطقـين بغـير العربيـة. فـلا سـيما في هـذا

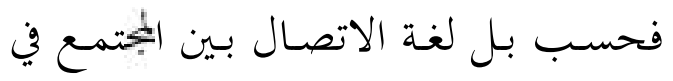


كانت اللغة العربية اللغة الأجنبية

عنــ الإندونيسـيين، فيحتـاج تعليمها إلى الطريقة والأساليب الخاصة. في تعليم اللغة العربية لغير الناطقين بها عناصر مهمة مثل المنهج الدراسي، والمواد الدراسية، والطرق،

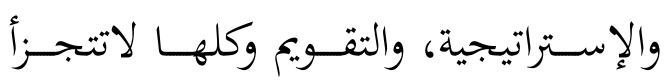
بعضهاعن بعض. التعليم الـذي لا يهتم

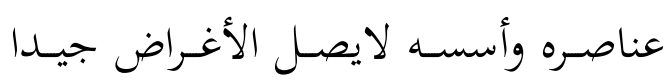

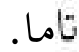

وكل مـا يتعلق بتعليم اللغة العربية

والمشـكلات عن التعريـب فيأثر إلى تعليم اللغـة العربية سواء كـان تعليم علوم اللغـة العربية (علم الأصوات، والنحو، والصرف)

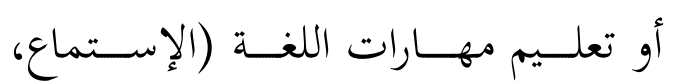
والكلام، والقراءة، والكتابة). وهذه المقالة تغـرض لتصـور طـرق التعريـب و أثرهـا في تعليم اللغة العربية لغير الناطقين بهما. المباحث أ. مفهوم التعريب

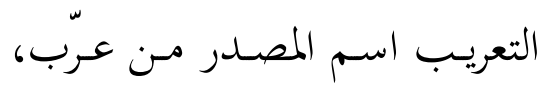

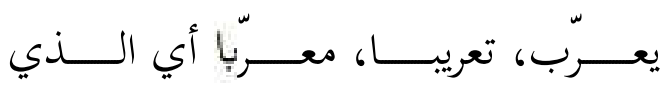

العصــر عصـر رقمـي لا تتحددمعاملـة

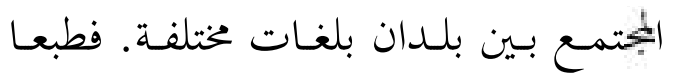
يأثر هـذا الأمـر اللغـة كوسيلة يستعملها الإنســان في الإتصــال. ومــن مظــاهر المشكلات استعمال المفردات التي لاتوجد في العربية. اذا توجد الكلمات والمصطلحات العجمية لا معنى لها في العربية فلا يجري بمـن شـاء، بـل يجـري القواعـد عنها.سـرعة

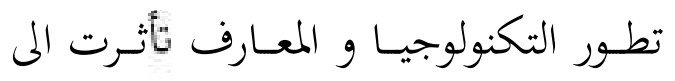
تطور الكلمـات والمصـطلاحات الجلديـدة في اللغـة العربيـة. مثـل كلمـة "internet"في الإندونيسية فظهرت المشكاتلات في تعليم

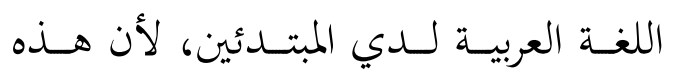

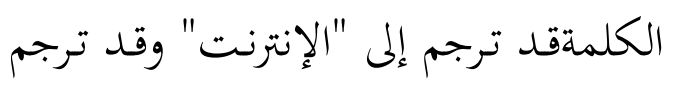
إلى كلمة "الشبكة". لأكها لم توجد في اللغة لتردة العربية من قبل، فلذلك يحتاج إلى القواعد لترجمـة الكلمـات والمصططلاحات الجلديـدة مـن العجميـة إلى العربيـة (في علـم اللغــة العربية يسمى "التعريب"). 
هنـا العرب البـدوي حتى القـرن الرابع من

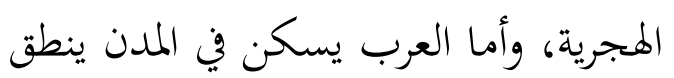
بالعربيـة الفصـيحة حستى القـرن الثـاني مـن الهجريـة، ويسـمى هـــا العصــري عصـر العرس الإحتجــاج. بعـض النظــر عـن هــــا الإخــتلاف مـن التسـميات والتعريفــات المذكورة أن نقل اللفظ العجمي إلى اللغة

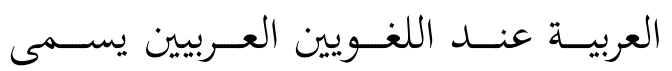
التعريب. - متربت

\section{ب.تطور التعريب}

وقع التعريب منذ زمان قديم، بل

من العصر الجاهلي. في ذلك العصر وقع الإتصـال اللغوي بـين اللغـة العربيـة واللغـة الأخرى خلال الغزو والهجرة والتجارة وكل

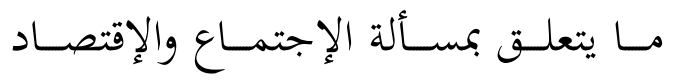
والعلوم. اتصلت العرب بالأمم البحاورة لهم كــالفرس والأحبــاش والـــروم والســــان وغسيرهم إلى جانـب إخـواهم السـاميين في العصر الجاهلي وبعد الإسلام وزاد اتصالهم

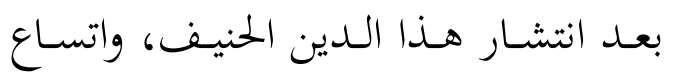

محمد بن ابر اهيم الحمد. فقه اللغة مفهومه وموضو عاته ص وقضاياه.
جعلعربيا.وعرفـه الإمـام السـيوطي بقولـه

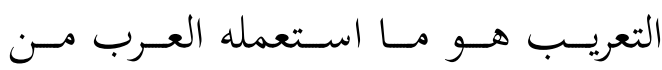
الألفـاظ الموضـوعة لمعـان في غير لغتها. وين التعريـف الأخــ هـو اللفــ العجمسي غيره العرب بالنقص أو الزيادة أو القلب.

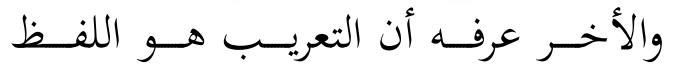
العجمي الذي استعملته العرب بأسلوبهم وهجاتَم . ومن تلك التعريفاتنستنبط أن

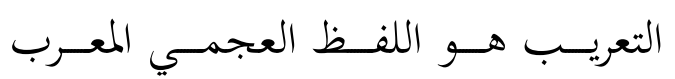
باعتماد أسلوب قواعد اللغة العربية. هنــاك مصــطلاحات عديــات

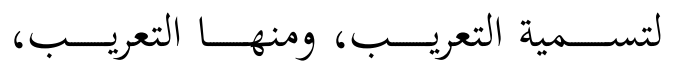
والدخيل، والمولّد. ولكن علي عبد الوافي ومنه

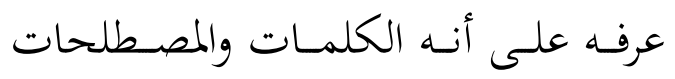
العجميـة يـدخلها النـاطق الفصحي، وأمـا

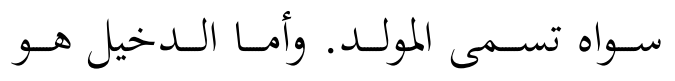
الكلمات والمصطلحات العجمية يدخلها الناطق الفصحي سواء قبل دخول الإسام

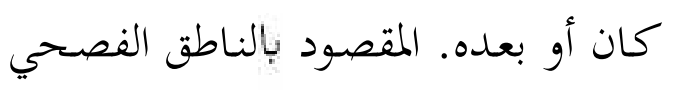

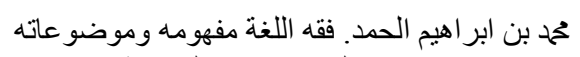

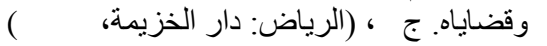
إميل بديع يعقوب. فقه اللغة العربية وخصائصها. ج العلم، (بيروت : دار العلم، بعل 
تطور العلوم والتكنولوجيـا في العـالم غير مباشر يأثر إلى تطور اللغة العربية، لأهـا

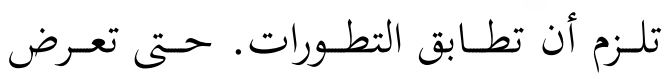
وجودهـا كلغـة عالميـة في الحـدث العولمـة

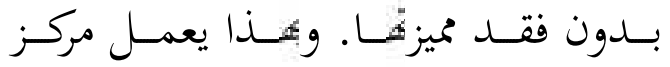

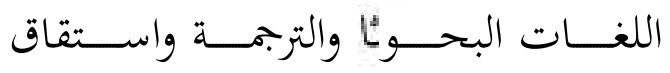

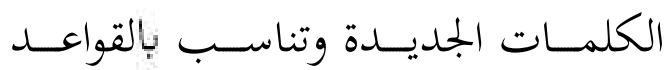
المقررات في اللغة العربية للغويين. ج. تحديد التعريب هنـاك إختلافـات بين العلمـاء في

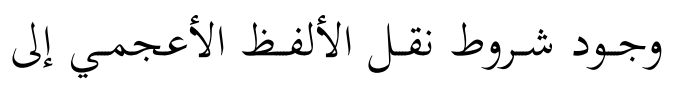
اللغة العربيـة، فبعض العلمـاء يشترط في

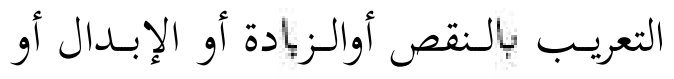

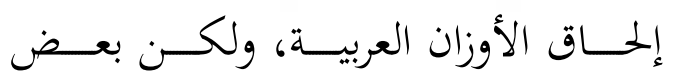

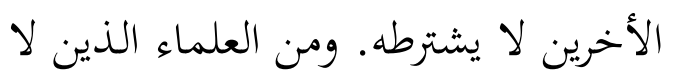

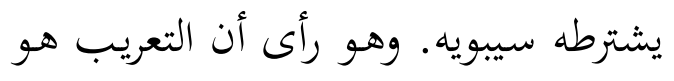
تكلم العرب بالكلمة الأجنبية بالإطلاق،

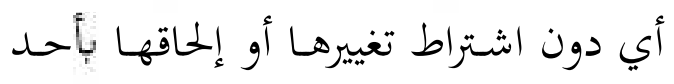
الأوزان العربية. لكن الألفاظ المشار إليها

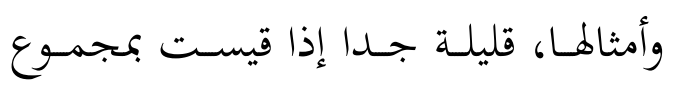

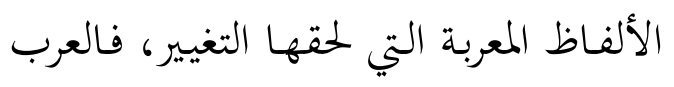

الدولة الإسلامية. فبإذا أضيف إلى ذلك

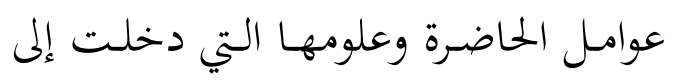
العرب وجدنا كثيرا من ألألفاظ الأجنبية العلمية والحضارية تدخل إلى نطاق اللغة العربية. وهذا أمـر طبيعي،فلا يمكن للغة أن تكون أمنا بعد أن تتصل بلغة أخرى

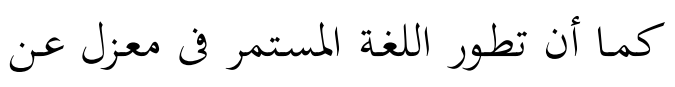
كل تأثير خارجي يعد أمرا مثاليا لا يكاد يتحقق في أية لغة بل على العكس مـن

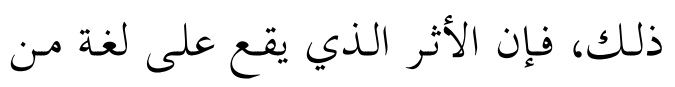

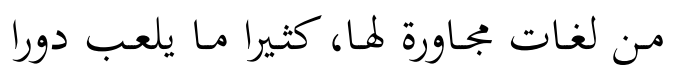

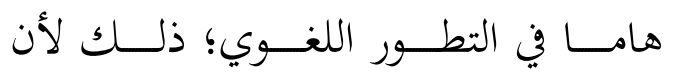
احتكاك اللغات ضرورة تاريخية، واحتكاك اللغات يؤدي حتما إلى تداخلها.

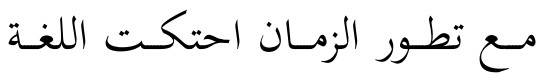

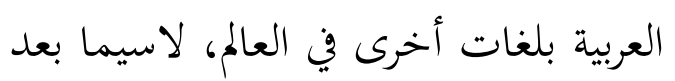

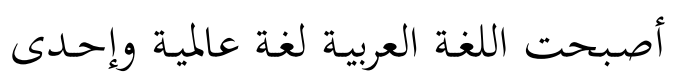

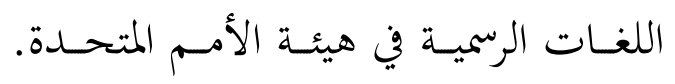

عبد الغفار حامد هلال. العربية وخصائصها وسماتها. ج

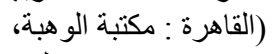
ف فصول في فقه العربية.

(القاهرة: مكتبة الخانجي، 
تغيير الصيغة الملائمة. ومن جانب الصريف

والنحـوي مثـل إشـتقاق الكلمـة و قيـاس

صيغ التثنية والجمع والتصغير ودخول لام

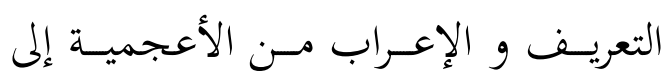

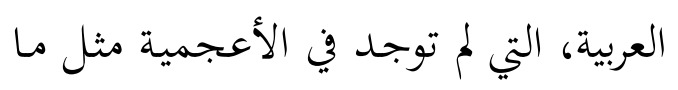

يكون في قواعد اللغة العربية.

وإذا نلاحظظ في الكلمـات المعربـة

فنجد التغييرات ومنها :

() إبـدال حـرف بحـرف نحسو جــرم

معرب كرم الفارسية بمعنى الحر،

ب) إبـدال حركـة بحركـة نحـو سـرداب

معرب سَرداب بمعنى بنـاء تحـت

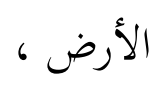

ب) زيادة شيئ نحو أرندج معرب من

$$
\text { رنده الفارسية } 6
$$

ع) نقص شيئ نحو بكرج معرب من

نبهره أي باطل ومعناه الزغل.

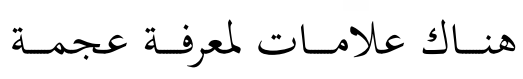

الكلمة، ومنها : (الما

\footnotetext{
عبد الغفار حامد هلال. العربية وخصائصها وسماتها. إميل بديع يعقوب............... فقه اللغة العربية وخصائصها....
}

قلمـا يعربون كلمـة، مـالم يردوهـا إلى كلمـة

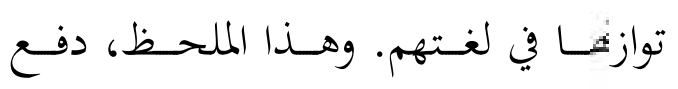
بعضهم إلى جعل التغيير والإلحساق بأحسد الأوزان العربية شرطا للتعريب.

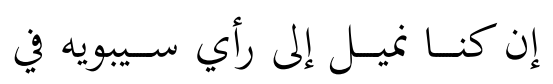

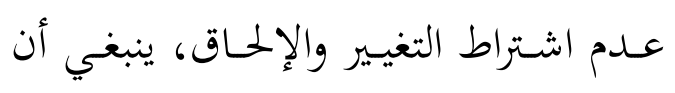
نقـف في ذلـك عنسـ حسـ حسـود. و إلا تكاثرت الكلمات الأعجمية ذات الأوزان

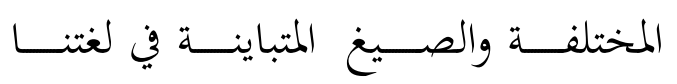
الفصسحى. وخرجـت بـذلك عـن صسورةّا وشكلها. وعادت لغة خلاسية لاعربية ولا أعجميـة كسائر اللغـات العربية العامية في مختلف الأقطار العربية.

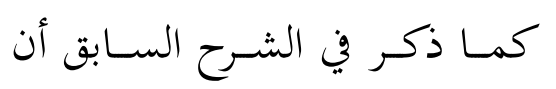
العرب غالبا لاتكلم الألفاظ مثل الأجنبي،

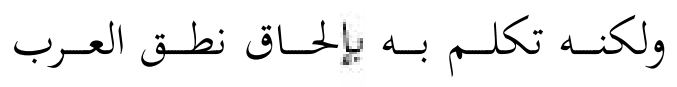
والطبعي العربي. كانت التغييرات كثيرة من التعريب، وهي ثلاثنة أقسام وهي الجانب

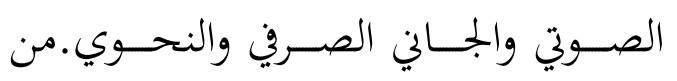
جانب الصوتي تغيير الحرف غير الملائم و إميل بديع يعقوب. فقه اللغة العربية وخصائصها......... 
دخيل الألفاظ الأعجمية إلى اللغة

العربية أسهل الطريقة في التعريب. و

يلزم أن يهـتم محيـزات اللغـة العربيـة،

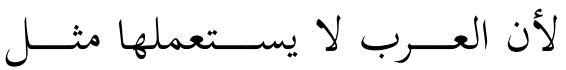

الأعجمـي بـل باتفـاق قواعـد اللغـة

العربيـة. هنـاك تغيـيرات في التعريـب

يكـــه الطريقـة، وتنقسـيم إلى ثلاثـة

أقســام وهــي التغيـير مــن جانــب

الصوتي، و من جانب الصرئ، ومن

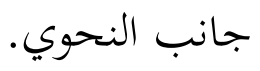

أ) التغيـير مــن جانــب الصــوتي

إبـال الحرف المناسب و تغيير

الصـــيغة المناســــة. في علــمـ

الصـوت التغيـيـر نوعـان وهمــا

فونميك هو تغيير الصوت يتعلق

بعنى الكلمة وفونتيك لا يتعلق

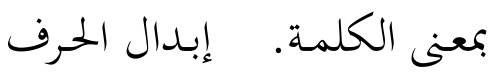

غـير المالائسم بأن لـيس جميــع

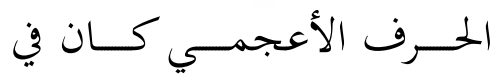

عبد الغفار حامد هلال. العربية وخصائصها وسماتها.

12 Abdul chaer,

LinguistikUmum,Jakarta : Rinekacipta, 2007

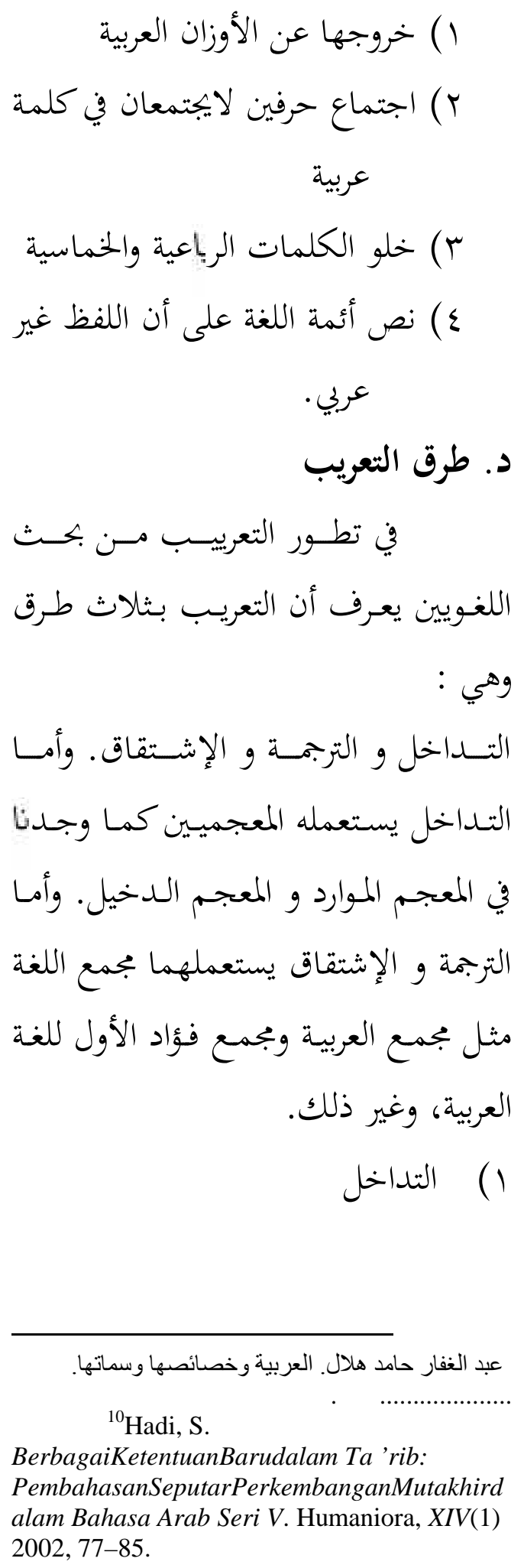
alam Bahasa Arab Seri V. Humaniora, XIV(1) 2002, 77-85. 
جمع، وفي قواعد العربية أن كل كلمة جمع

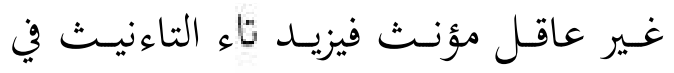
آخرها صارت "الفرنجة". ץ) عدام التغيير

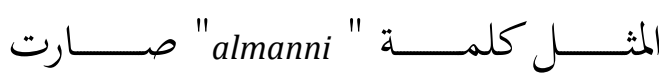

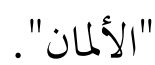

وســوى تغيـير الصـوت بإبــدال

الحرف ومما يبدل الحركات، لأن الحركات

مخصـوص في العربيـة. التغيسيرات بإبـدال الحركات وهو ( ) إبدال الصوت /e/ بحركة

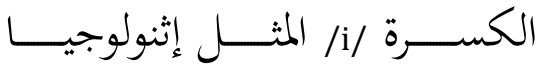

إبــــ/ (ethonlogia) بحركة الفـتح /a/ المثـل كشـير مـن اللغـة

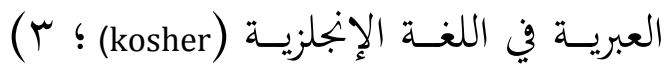

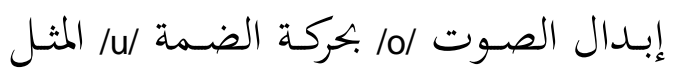
كنسلتو.

ب) التغيير من جانب الصريف

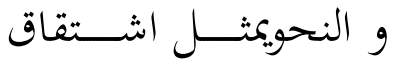

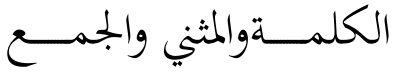

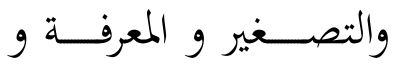

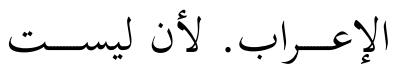

Ibid

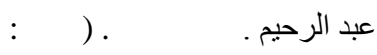

العربيـة. مـن البحــث الــــي

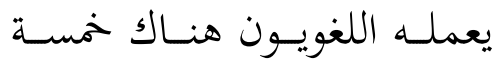

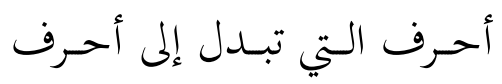

العجم وهي ب، ف، ق، ك،

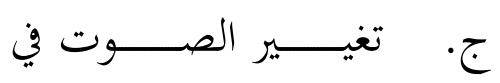

التـداخل يتقـف بمناسبة كـون

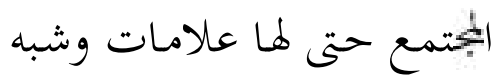

بأصوات أحرف الهجائية.

وأما التغييرات من جانب الصوتي

في التعريب من نتيجة البحث يدل عليها

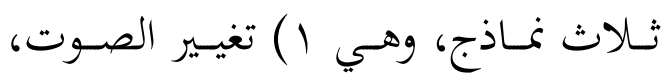

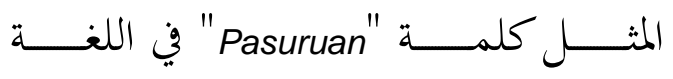
الإندونيسـية مكتـوب ب"باسـوروان" في

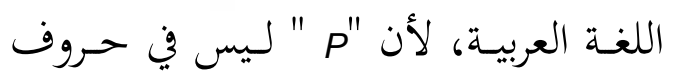

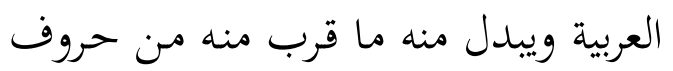
العربية. ץ) تغيير الصوت والزيادة، المثل

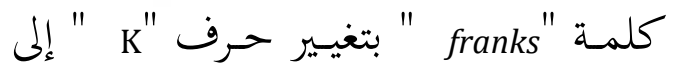
حرف " ج" و حرف " s" يدل على أهما عبد الغفار حامد هلال. العربية وخصائصها وسماتها.

${ }^{14}$ Muhammad afif Amrullah, Analisis Perubahan Fonologi sdalam pembentukan kalimah mu'arabah, Jurnal Adabiyat Vol. 4 No. 2, 2017, 217-226 


\section{6 "Philologist}

"

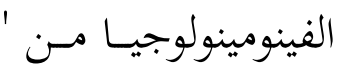

Phenomenologist

كلمـات الصـفات الـتي

" -an, -ic, -al, -ive"

فتزيـــ ياء النسـبة، المثـل

أنيمي من "anemic"
اللغـــة الأعجميــة مثــل

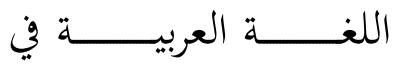

الأوزان.

ومـــن نتيجــــة البحـــــ

للشمس الهادى الموضوع

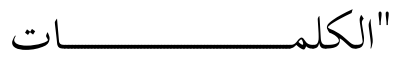

والمصــــات طات

الأعجميــة في العربيـة"،

أن بعـد التــاخل بعـادة

الـــتلفظ في العربيـــــة ثم

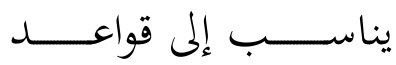

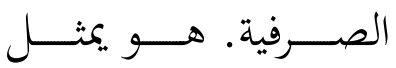

الكلمــات في الإنجلزيــة

الـتي أخرهـا "ist" و " er "

فتصــــــى الكلمـــــــات

الجلديدة في العربيـة بزيادة

ياء النســــــــة. المثــــــلـل

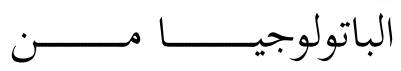

6"pathologist"

الفيلولوجيــا مــن "

${ }^{18}$ Hadi, Kata dan istilah Asing dalam

Bahasa Arab.Humaniora, (1)

1995,.....hlm 113-120 
إشتقاق الكلمات الجديدة في علوم وهي علم الأصوات و كتابة الأحرف

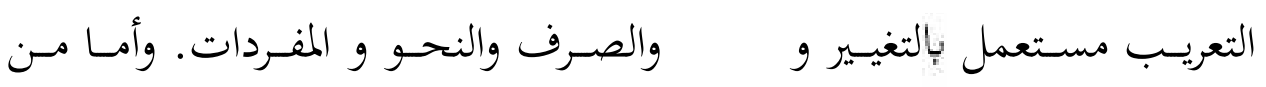
اتفـاق الأوزن في الصـرفي نهـو مهـارات اللغـة مهـارة الإستماع والكـلام

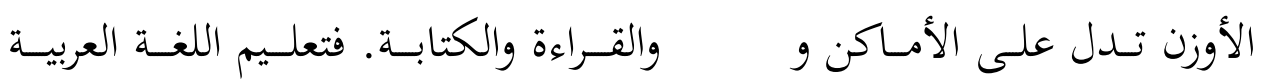
الألات و الأزمنة. المثل كلمة وخاصة لغير الناطقين بها يمتاج إلى اهتمام

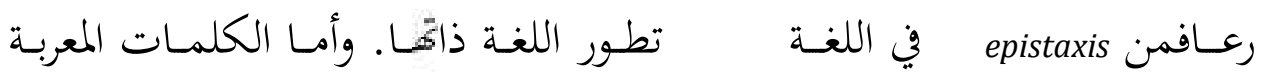
الإنجلزيـة و زهـار مـن florist و مهمة للطلاب الأجنبي أن يفهموهـاكي

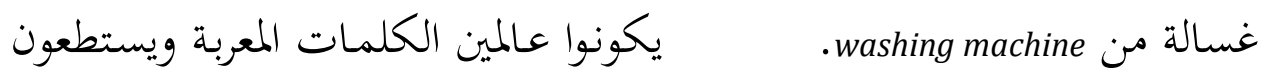

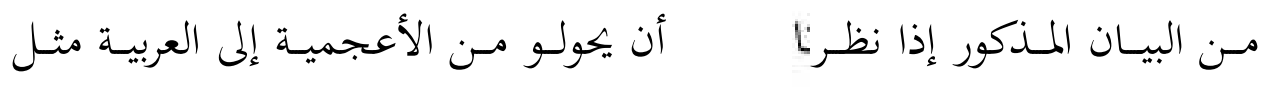

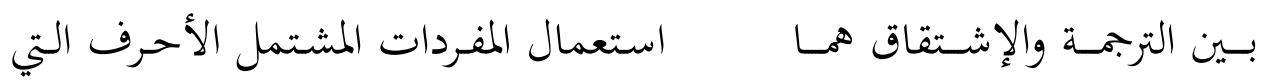

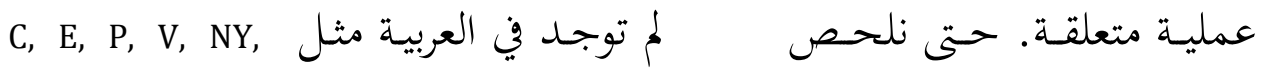

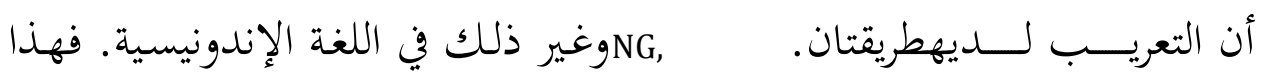

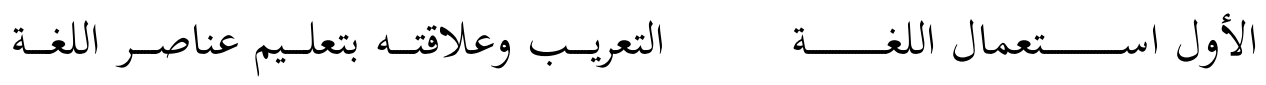
الأعحجميـة بإلحـاق أحسرف والمهارات يحتاج إلى الإستيرابتية. اللغة العربيـة، والثـاني إشتقاق التعريب في تعليم عناصر اللغة

$$
\begin{aligned}
& \text { العربية } \\
& \text { الكلمــات الجديــــة لإبــــال }
\end{aligned}
$$

فينبغـي علسى المدرســين أن اللغة الأجنبية.

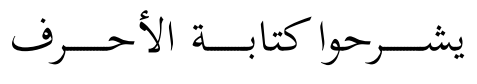

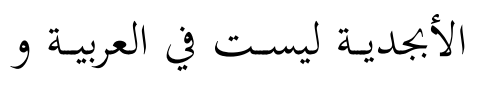
هـ التعريسب في تعلـيم اللغـة

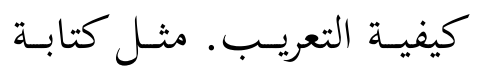

تعلـيم اللغــة العربيـة يحتـوى على لـ

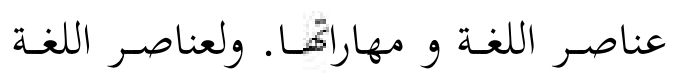




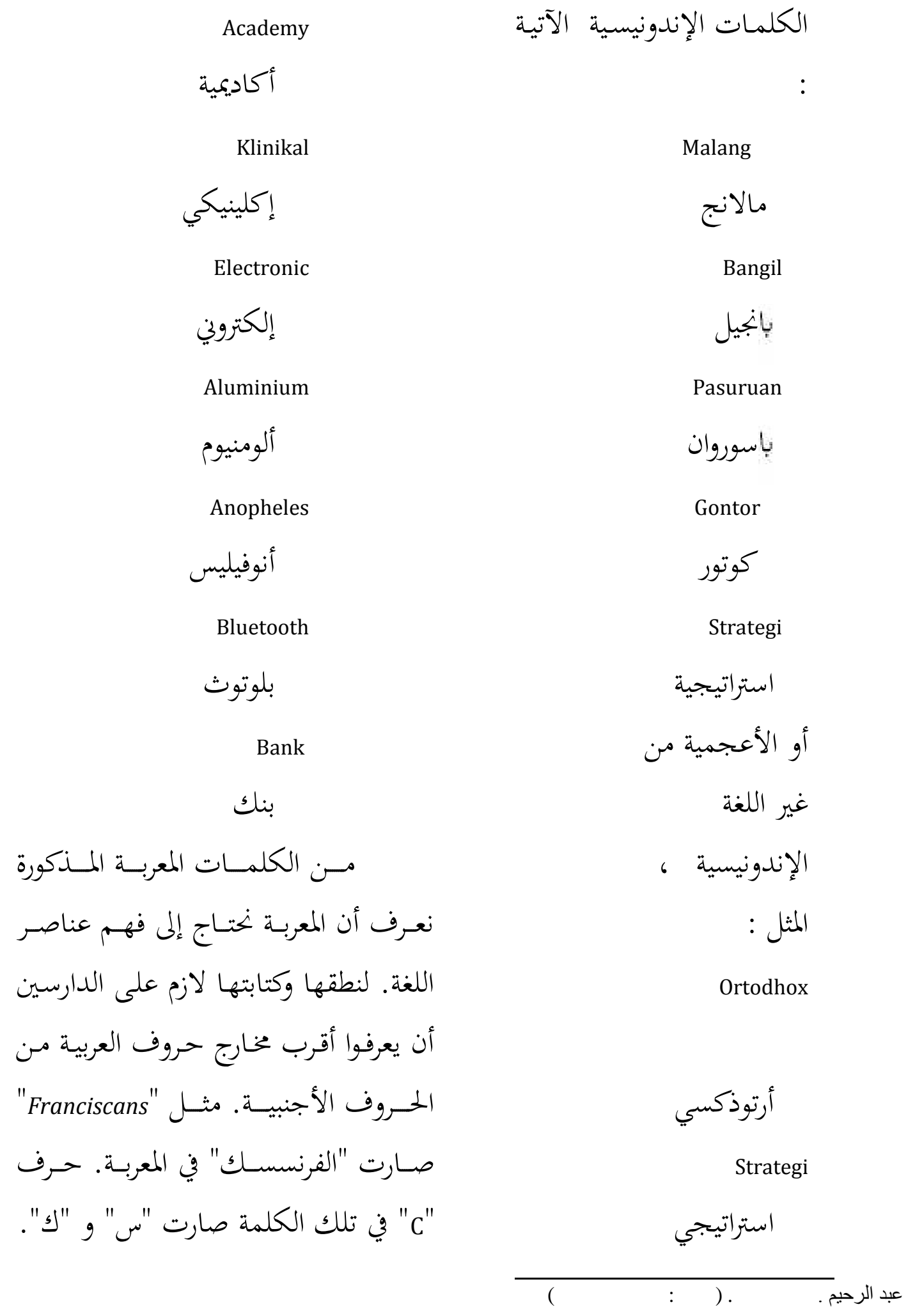




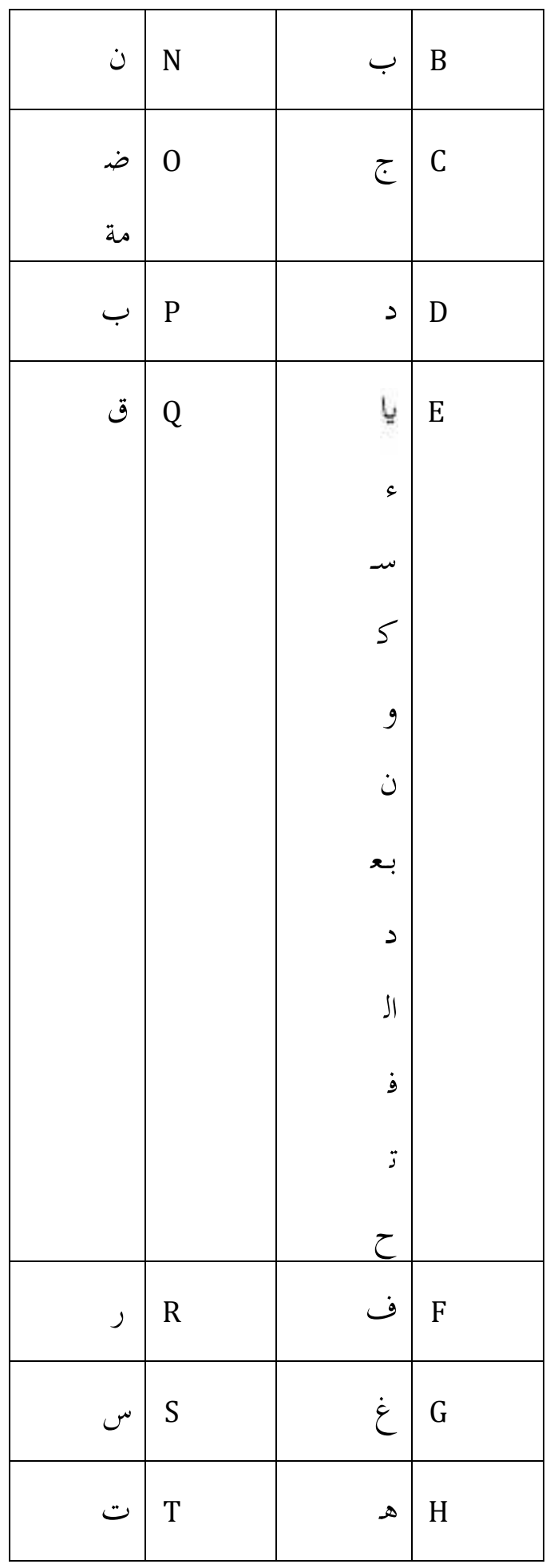

إن في اللغة الإندونيسية سبع نغمة

التي لا تؤدي منها حروف اللاتينية

هي , C, E, P, V, NY, NG. وأما كتابة

حـــروف الهجائيــة العربيـــة مــن

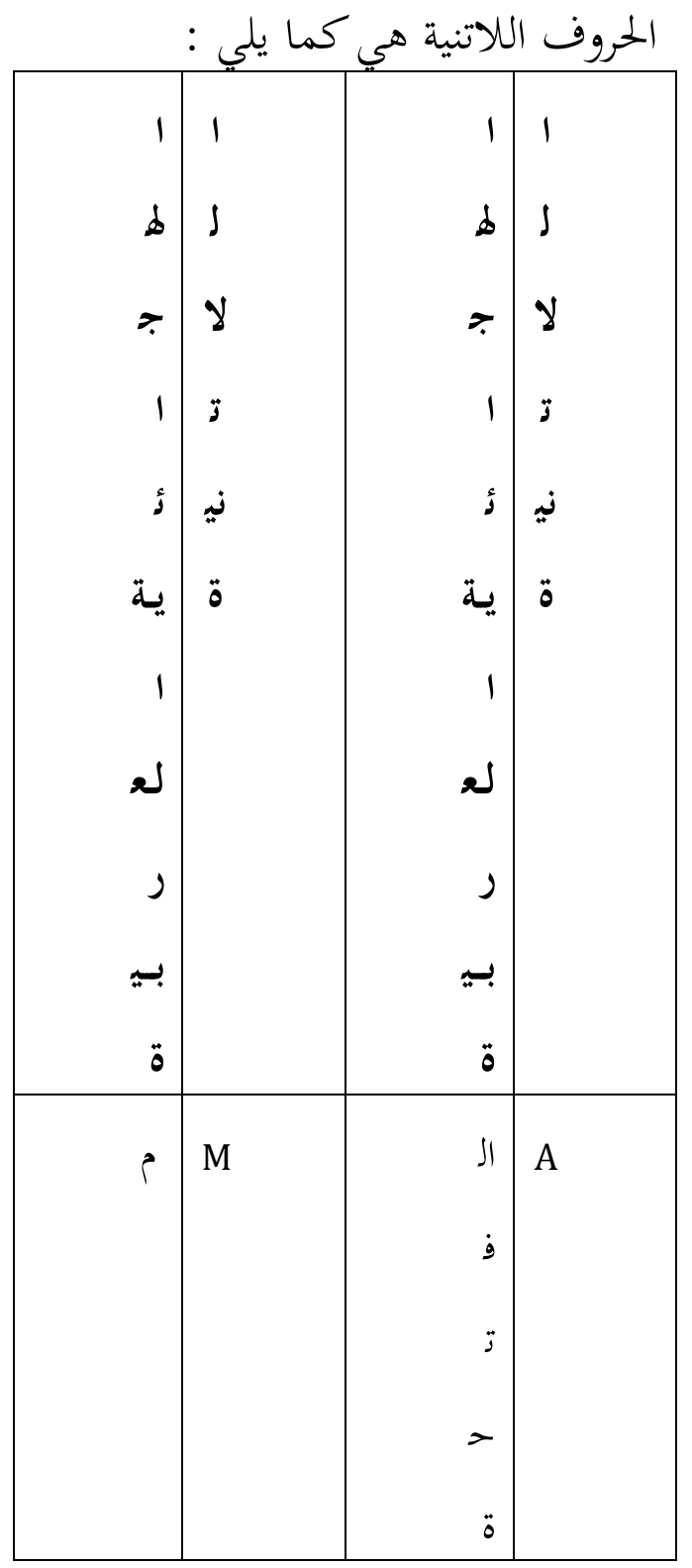


كتاباتها من اللغة الأولى. المثل كتابة كلمة

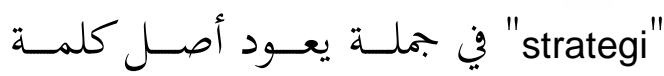

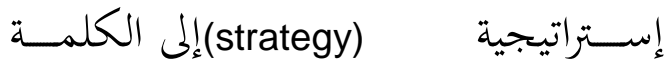
اليونانيــ(strategia)والـتي تعـني البراعـة

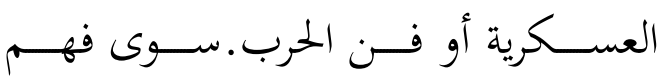

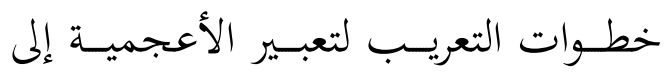

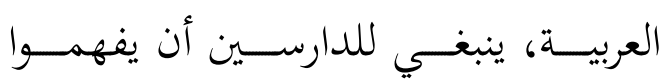

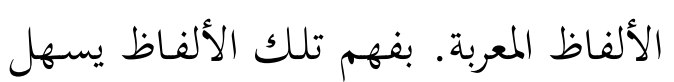

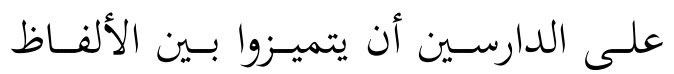
العربية والألفاظ الأعجمية. r. التعريب في تعليم مهارات اللغة العربية سيواجه الدارسون الصعوبات في الكلمات المعربة في تعليم مهارة اللغة إذا لم يفهمـوا عـن التعريـب. في تعلـيم مهــارة

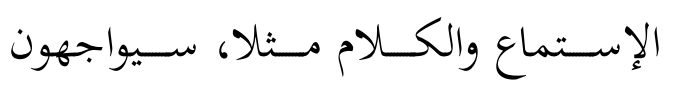
المشكلات لتفريق جوهرة أصوات الحروف

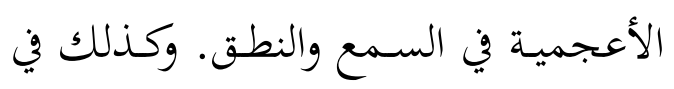
مهــارة القـــراءة والكتابــة، سـيواجهون

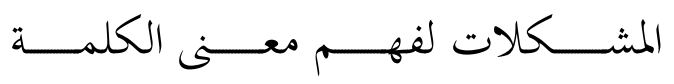

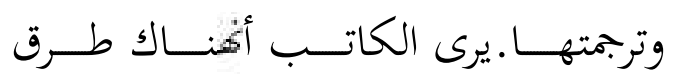
وخطوات يمكن ان يستعمل المدرسون في

\begin{tabular}{|c|c|c|c|}
\hline ضم & $\mathrm{U}$ & كم & I \\
\hline 9 & V & ج & $\mathrm{J}$ \\
\hline 9 & W & 5) & $\mathrm{K}$ \\
\hline س & $X$ & ل & $\mathrm{L}$ \\
\hline j & $\mathrm{Z}$ & ي & $Y$ \\
\hline
\end{tabular}

و يشـرح المدرسـون النحـوي مـــا

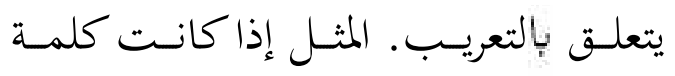
الأعجمية دلت على الصفة فيزاد فيها ياء النسـبة، أو على الجمـع فيناسـبـ بموقـع الكلمة (زيادة الألف والتاء لجمع التأنيث، والواو النون لجمع المذكر السالم في الرفع، والياء والنون في النصب والجر). وأما الخطوات الممكنة للمستعملة فهـي (1) ضــبط الألفــاظ الأعجميــة للأصوات العربية حتى يسهل نطقها بدون

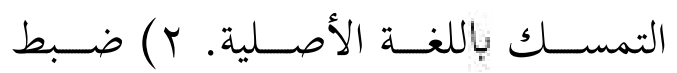
الألفـاظ الأعجميـة لصـيغ العربيـة في علـم

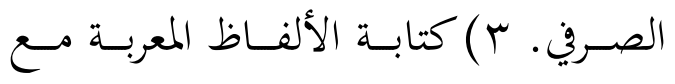


ع) يطلــب المعلمـــون الطــلاب أن يستعملوا اللغـة الفصـيحة مـن الفـابـ

$$
\text { العامية. }
$$

ينبغـي على الطـلاب أن يطلبـوا

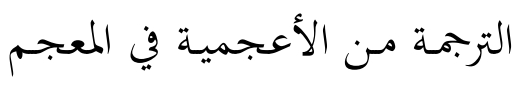

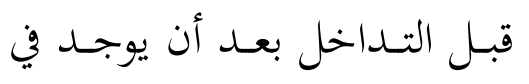

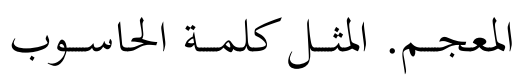

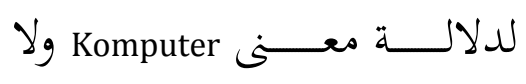

$$
\text { تكتب بالكمبيوتر. }
$$

يطلب المعلمون على الطلاب أن بـاب

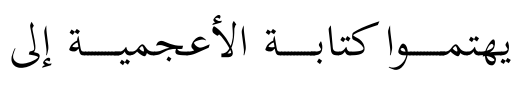

العربية من الأحروف الأعجمية

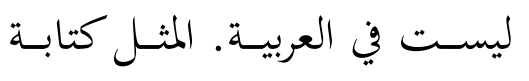

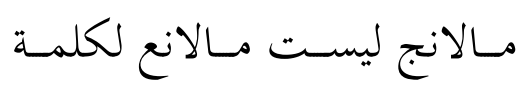

. Malang

الخايتمة

التعريب شيئ ضروري للغة العربية

لقبول تطور الزمان بتطور العلوم والثقافة

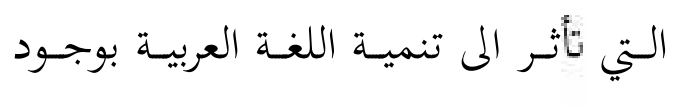

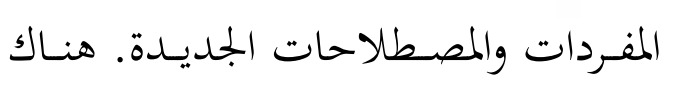

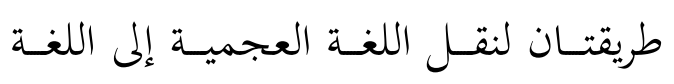

تعلـيم اللغــة اللغــة العربيـة عـن التعريـب، :

1) يعرض المعلمون صيغ الألفاظ

المعربة حتى يفهم الطلاب

النصوص العربية التي لميها

الألفاظ المعربة. المثل " أظهر التية

تقرير منظمة فريدوم هاوس

الأميركية لمؤشرات الديموقراطية

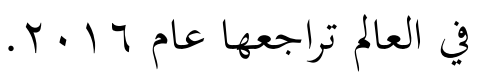

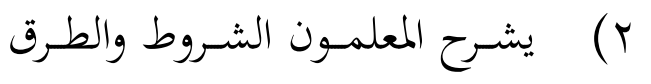

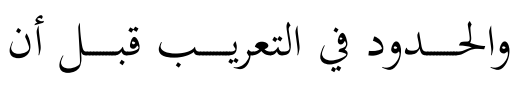

يعلموا مهارات اللغة (الإستماع،

الكالام، القراءة، الكتابة)، مثل

زيادة ياء النســـبة، و إبــــال

الأحروف المناسبة، وغير ذلك الك الكاء

كما شرح في السابق.

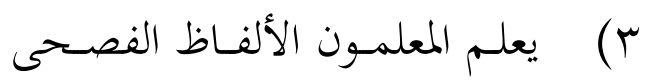

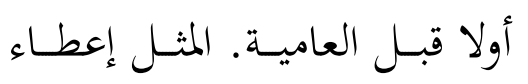

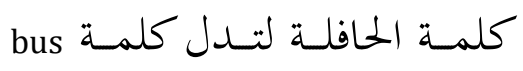

أولا قبل أتوبيس ولو كان أسهل 


$$
\begin{aligned}
& \text { إميل بديع يعقوب، } \\
& \text { العربية وخصائصها. بيروت }
\end{aligned}
$$

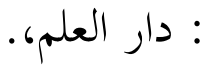

$$
\begin{aligned}
& \text { عبد الغفار حامد هلال، ع . . ب العبية } \\
& \text { وخصائصها وسماها. القاهرة } \\
& \text { ( } \\
& \text { رمضان عبد التواب، } 999 \text { ـ ـ فصول في } \\
& \text { فقه العربية. القاهرة: مكتبة }
\end{aligned}
$$

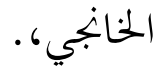

$$
\begin{aligned}
& \text { عبد الرحيم .0عجم الدخيل، } 1 \text { 1 . r. } \\
& \text { دمسق: دار القلم. }
\end{aligned}
$$

Amrullah, Muhammad Afif, 2017.

$\begin{array}{lr}\text { Analisis } & \text { Perubahan } \\ \text { Fonologis } & \text { dalam } \\ \text { pembentukan } & \text { kalimah }\end{array}$
mu'arabah, Jurnal Adabiyat Vol. 4., No. 2.

Chaer, Abdul, 2007, Linguistik Umum, Jakarta : Rineka Cipta.

Hadi, Syamsul, 1995. Kata dan istilah Asing dalam Bahasa Arab.Humaniora, 1.

Hadi, Syamsul, 2002. Berbagai Ketentuan Baru dalam Ta'rib: Pembahasan Seputar Perkembangan Mutakhir dalam Bahasa Arab. Humaniora, XIV(1).

Muhammad Afif Amrulloh, 2017. Ro'fat Hizmatul Himmah. Analisis Perubahan Morfologis Pembentukan Ta'ribdan Pembelajarannya, Tadris, 2.

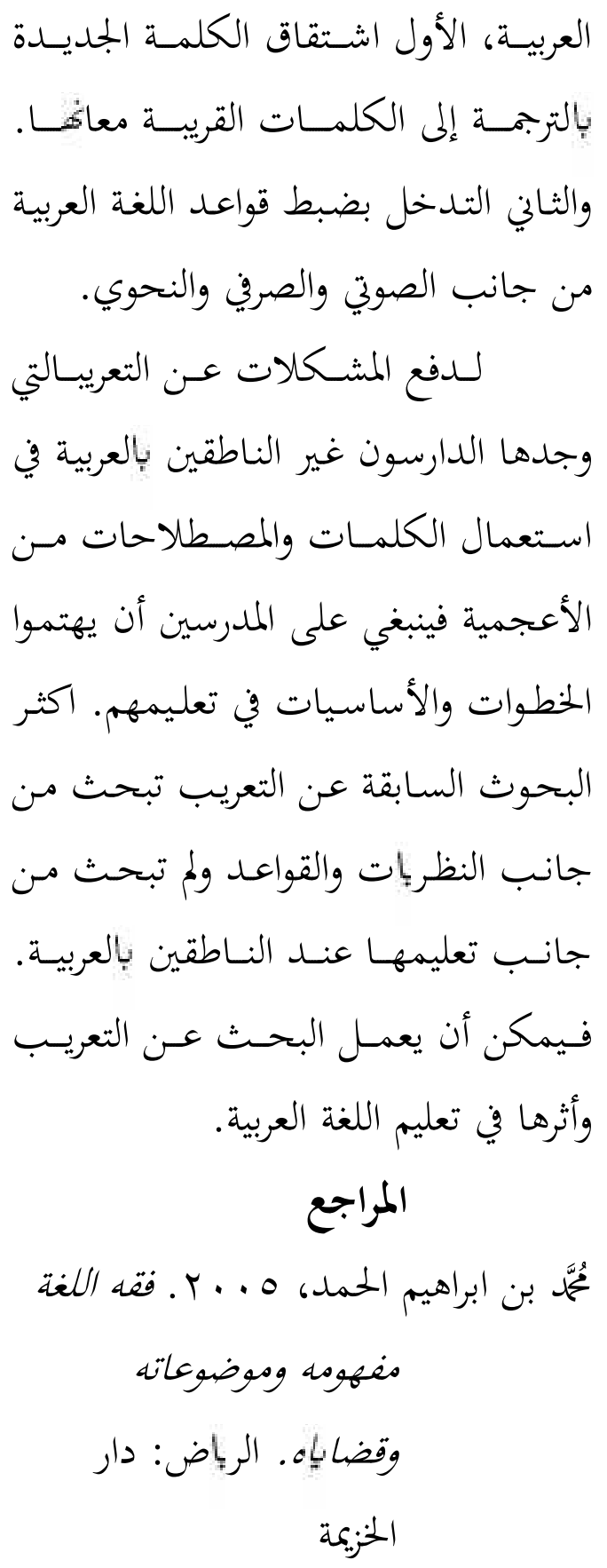

